\title{
VINCULAÇÃO DOS ÓRGÃOS DA IMPRENSA AO ESTADO DE INOCÊNCIA
}

CONNECTION BETWEEN THE MEDIA AND THE PRESUMPTION OF INNOCENCE VINCULACIÓN DE LOS ÓRGANOS DE PRENSA AL ESTADO DE INOCIENCIA

\section{NEREU JOSÉ GIACOMOLLI ${ }^{1}$}

DENISE LUZ²

Resumo: Este trabalho objetiva analisar o estado de inocência como direito fundamental sob as perspectivas de sua natureza, conteúdo, estrutura normativa e funcionalidade, tendo a sociedade da informação, ou sociedade em rede, como paradigma. O problema de pesquisa é se a exposição pública pelos veículos de comunicação de massa de casos penais pendentes de julgamento definitivo viola ou não o estado de inocência. E, em caso afirmativo, como a estrutura normativa é atingida e quem é o destinatário da norma: apenas o Estado ou também os particulares. O estudo baseia-se na jurisprudência dos tribunais internacionais de direitos humanos como método de abordagem, analisando, dialeticamente, os possíveis limites à liberdade de expressão frente ao estado de inocência. A conclusão é de que o estado de inocência, embora tenha natureza processual, é direito-garantia fundamental com eficácia vertical em relação aos media, sob o aspecto de norma de tratamento.

$1 \quad$ Doutor em Direito Processual Penal pela Universitad Complutense de Madrid. Professor na Pontifícia Universidade Católica do Rio Grande do Sul - PUCRS - do curso de graduação em Direito e dos cursos de mestrado e Doutorado em Ciências Criminais, em Porto Alegre, Rio Grande do Sul, Brasil. Advogado e consultor jurídico (nereu@giacomolli.com).

2 Mestre e doutoranda em Ciências Criminais pela Pontifícia Universidade Católica do Rio Grande do Sul - PUCRS, com auxílio CAPES. Professora da graduação em Direito na Universidade de Pernambuco UPE, em Arcoverde, Pernambuco, Brasil. Advogada. (dnluz@terra.com.br). 
Palavras-chave: Estado de inocência. Liberdade de expressão. Sociedade da informação. Veículos de comunicação.

Abstract: This study analyzes the presumption of innocence as a fundamental right, considering its nature, content, normative structure and functionality, with the information society or network society as a paradigm. The research question is whether public exposure via mass communication channels of criminal cases awaiting a final decision violates the presumption of innocence, and if so, how is the normative framework affected and who does the norm target: only the State, or individuals as well? The study is based on the jurisprudence of international human rights courts as an approach method, dialectically analyzing the possible limits to freedom of expression in the presumption of innocence. The conclusion is that although procedural in nature, the presumption of innocence is a fundamental right that is vertically effective in relation to the media, as a rule of treatment.

Keywords: presumption of innocence. Freedom of expression. Information society. Communication channels.

Resumen: Este trabajo objetiva analizar el estado de inocencia como derecho fundamental bajo las perspectivas de su naturaleza, contenido, estructura normativa y funcionalidad, teniendo la sociedad de la información, o sociedad en red, como paradigma. El problema de la investigación es si la exposición pública por los medios de comunicación de masa de casos penales pendientes de juicio definitivo viola o no el estado de inocencia. $Y$, en caso afirmativo, como la estructura normativa es cumplida y quien es el destinatario de la norma: el Estado o, también los particulares. El estudio se basa en la jurisprudencia de los tribunales internacionales de derechos humanos como método de abordaje, analizando, dialécticamente, los posibles límites a la libertad de expresión frente al estado de inocencia. La conclusión es que el estado de inocencia, aunque tenga naturaleza procesal, es derecho-garantía fundamental con eficiencia vertical con relación a los medios, bajo el aspecto de norma de tratamiento.

Palabras-clave: Estado de inocencia. Libertad de expresión. Sociedad de la información. Medios de comunicación. 


\section{INTRODUÇÃO}

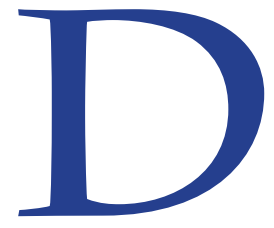

estaca-se, desde já, que não se objetiva apresentar resposta definitiva às angústias intelectuais aqui expressadas, mas lançar questionamentos e reflexões que possam, de algum modo, contribuir ao amadurecimento democrático da sociedade brasileira, cujo papel e responsabilidade são, também, da Academia. Este trabalho aborda o estado de inocência como direito fundamental e, como tal, com força cogente e voltado à maior realização possível, na perspectiva de sua natureza, conteúdo, estrutura normativa e funcionalidade.

O problema posto, ao qual se pretende dar algumas respostas, é se a exposição pública pelos veículos de comunicação de massa de casos penais pendentes de julgamento definitivo viola ou não o estado de inocência. E, em caso afirmativo, como a estrutura normativa é atingida, quem é o destinatário da norma: apenas o Estado ou também os particulares. A pesquisa partiu das hipóteses de que há violação ao estado de inocência quando o imputado é apresentado publicamente como autor do fato criminoso antes do trânsito em julgado; que essa violação se dá na sua dimensão de norma de tratamento; e que particulares podem ser destinatários da norma. Essas respostas prévias e provisórias se confirmaram durante a investigação e integram as considerações finais do presente artigo. Atingiu-se o resultado da investigação com a utilização da metodologia dialética para analisar possíveis limites à liberdade de expressão, quando confrontada com o direito-garantia do estado de inocência.

A partir de uma investigação temporalizada - consentânea com a sociedade de informação -, e baseada na jurisprudência dos tribunais internacionais de direitos humanos, o presente artigo pretende avaliar se a exposição midiática dos imputados (suspeitos, acusados ou réus), antes do pronunciamento judicial definitivo, viola ou não o estado de inocência.

Cientes da instantaneidade caracterizadora da sociedade de informação, na qual a apreensão da hipótese acusatória engendra "verdades imediatas" e inconciliáveis com o tempo de construção dialética da verdade no processo, admite-se debater sobre possíveis limites à liberdade de expressão para salvaguardar o estado de inocência. 
Focados nesse objetivo, serão analisadas as características gerais da sociedade de informação, no primeiro tópico, para, logo após, dar visibilidade à objetivação do imputado no processo penal e fora dele. No terceiro momento será abordado o tratamento jurídico dado à presunção de inocência (rectius estado de inocência) no Brasil, mostrando sua equivalência material e juspolítica com a presunção de não culpabilidade penal. Posteriormente serão evidenciados a natureza, a finalidade, a estrutura normativa, bem como os modos de manifestação desse direito fundamental, conforme jurisprudência dos tribunais regionais de direitos humanos da Europa e das Américas. Finalmente, verificar-se-á se o estado de inocência vincula também particulares (órgãos de imprensa) ou apenas o Estado e em que medida.

\section{A sociedade de informação}

O modo de vida social, na atualidade, passa por profundas transformações, promovidas pelo desenvolvimento da tecnologia da informação. A utilização da internet inaugurada, de modo restrito, nos Estados Unidos, na década de 70, veio a atingir dimensão global nos anos $90 \mathrm{com}$ a criação da world wide web $(w W w)$, a rede mundial de computadores, por obra de Tim Berners- Lee. ${ }^{3}$ Desde então, as ferramentas de comunicação disponíveis na web vêm se ampliando, e o número de usuários está aumentando, veloz e significativamente. ${ }^{4}$ Essas novas tecnologias promoveram enorme rapidez e dinamismo na transmissão da informação e na realização da comunicação, alterando o modo de viver em sociedade e a própria estrutura do pensamento contemporâneo. A velocidade com que a internet passou a fazer parte das atividades empresariais e da vida cotidiana das pessoas, em todo o mundo, nos últimos tempos, assim como a crescente adesão a esse modo de conexão global, está modificando a configuração das relações humanas e do modelo de sociedade em que se habita. Vive-se a (e na) "Sociedade da Informação", cujas principais características são a ausência de

3 V. MARQUES, Gil da Costa; CRESPO, Marcelo Xavier de Freitas. Um panorama sobre a Sociedade de Informação: o cloud computing e alguns aspectos jurídicos no ambiente digital. In: MENDES, Gilmar Ferreira; SARLET Ingo Wolfgang; COELHO, Alexandre Zavaglia P. (Coord.). Direito, Inovação e Tecnologia. São Paulo: Saraiva, 2015, p. 125.

4 Em CASTELLS, Manuel. A Galáxia da Internet: Reflexões sobre a internet, os negócios e a sociedade. Rio de Janeiro: Zahar, 2003, p. 8. 
fronteiras e as distintas formas de comunicação, relacionando-se constantemente com a produção e a disseminação de conteúdo digital. ${ }^{5}$

A tecnologia da informação, segundo Castells, promoveu, e está promovendo continuamente, uma nova sociedade, uma sociedade conectada globalmente a qual denominamos de sociedade em rede, "construída em torno das redes de comunicação da internet". Essa nova morfologia social é caracterizada pela flexibilidade e adaptabilidade; o espaço de fluxos e o tempo intemporal são as bases principais dessa nova cultura, a qual inclui a diversidade dos sistemas de representação. ${ }^{6}$ Vive-se uma transformação, não só tecnológica e econômica, mas também cultural, moldada por novos paradigmas (tecnológicos) capazes de dominar o espaço e vencer o tempo, como concebidos até recentemente. A comunicação pela internet anula distâncias, permite o processamento instantâneo da informação e a manifestação de novos valores em um frenético devir. ${ }^{7}$

Segundo Castells, a tecnologia da informação tem o mesmo valor histórico, no momento atual, que a revolução industrial teve para promover mudanças na forma de pensamento e comportamento social no séc. XVIII. A internet é símbolo dessa nova sociedade - sociedade em rede. ${ }^{8}$ Esse uso da tecnologia no processamento da informação atua como modo de produção (ou de produtividade) social, denominada por Castells de informacionalismo, como sucessão sociológica do industrialismo. Neste sistema, aplica-se conhecimento no processo de produção de bens. Desenvolver tecnologia no industrialismo consistia, basicamente, desenvolver e aplicar conhecimento na mecanização do processo produtivo, em substituição à força humana e na obtenção de fontes de energia. O objetivo de desenvolver tecnologia era obter crescimento econômico. $\mathrm{Na}$ era do informacionalismo, desenvolver tecnologia significa desenvolver conhecimento

5 Em MARQUES, Gil da Costa; CRESPO, Marcelo Xavier de Freitas. Um panorama sobre a Sociedade de Informação: o cloud computing e alguns aspectos jurídicos no ambiente digital, p. 124.

6 Em CASTELLS, Manuel. A Sociedade em Rede. São Paulo: Paz e Terra, 1999, p. 224.

7 O sentido de devir aqui empregado é o adotado pelo historiador das ideias Franklin Baumer. V. BAUMER, Franklin L. O Pensamento Europeu Moderno. V. II. Tradução de Maria Manuela Alberty. Lisboa: Edições 70. Original Modern European Thought publicado em 1977.

8 Em CASTELLS, Manuel. A Galáxia da Internet: Reflexões sobre a internet, os negócios e a sociedade, p. 226. Sobre o impacto da Revolução Industrial no pensamento ocidental, consultar: BAUMER, Franklin L. O Pensamento Europeu Moderno. V. I. Tradução de Maria Manuela Alberty. Lisboa: Edições 70. Original Modern European Thought publicado em 1977. 
para processar informação, objetivando atuar sobre esse mesmo conhecimento para fins de acumulação de conhecimento em si, promovendo a reestruturação e a expansão do sistema econômico capitalista. Neste, a comunicação é o centro da vida social. ${ }^{9}$

É nessa sociedade em que se vive e é nela que o Direito atua. Por isso, pensar o Direito (e os direitos) na contemporaneidade exige refletir as instituições jurídicas e as categorias dogmáticas do Direito, tendo essa sociedade como local de fala. Essa transformação social trouxe impactos significativos no âmbito de todos os direitos fundamentais, dentre eles, sem dúvida, o do estado de inocência no processo penal, ao que este trabalho se dedica.

\section{O imputado como objeto da informação}

Os meios de comunicação, como a televisão, especialmente as de canal aberto, e o rádio continuam sendo usados maciçamente. Aquele é o meio predominante no Brasil e este é o segundo mais utilizado no País, apesar de os brasileiros permanecerem mais tempo conectados à internet do que assistindo à TV. ${ }^{10} \mathrm{~A}$ diferença básica, quanto ao modo de funcionamento desses meios, no que interessa para este trabalho, é que a internet integra vários modos de comunicação diversos, como texto, imagens e sons de modo interativo e em conectividade instantânea e permanente. No mundo da internet não há limites para o alcance e a disseminação da informação. A televisão, em geral, possibilita apenas a recepção da informação em âmbito espacial delimitado, mas, mesmo assim, causa efeitos sobre o estado de inocência do indivíduo acusado de crime, quando exposto publicamente antes do trânsito em julgado da decisão condenatória.

O uso da internet facilita, amplifica e acelera a divulgação de informações, como as investigações policiais e os processos judiciais, os quais acabam recebendo importante repercussão, mormente quando envolvem figuras conhecidas do

$9 \quad$ Em CASTELLS, Manuel. A Sociedade em Rede.

10 V. BRASIL. Presidência da República. Secretaria de Comunicação Social. Pesquisa brasileira de mídia 2015: hábitos de consumo de mídia pela população brasileira. Brasília: Secom, 2014. Disponível em: <http://www.secom.gov.br/atuacao/pesquisa/lista-de-pesquisas-quantitativas-e-qualitativas-de-contratos-atuais/pesquisa-brasileira-de-midia-pbm-2015.pdf>. Acesso em: 27/11/2016. 
público ou quando o crime causa comoção, como vem ocorrendo intensamente no Brasil nos últimos anos. Exemplos da exposição do imputado (suspeito, acusado ou réu) tão logo sobre ele recaia a primeira suspeita de autoria ou participação criminosa podem ser encontrados nos casos Isabella Nardoni, Menino Bernardo Boldrini, Suzane Von Richthofen e tantos outros. Exemplos de ampla divulgação de operações policiais ostensivas no exato momento em estão sendo realizadas, com a divulgação da imagem de pessoas sendo presas cautelarmente são corriqueiros, como na chamada Operação Lava Jato realizada pela Polícia Federal do Estado do Paraná, em andamento desde 2014, em suas diversas fases, todas com ampla divulgação midiática. Nesse contexto, foram presos destacados empresários, detentores de cargos públicos e políticos, dentre os quais um senador da República, em pleno exercício do mandato. Um caso de grande repercussão que trouxe à tona a discussão sobre a legitimidade da divulgação de imagens no momento em que realizada a prisão foi o ocorrido na Operação Satiagraha da Polícia Federal, em 2008, quando ex-prefeito do Município de São Paulo foi filmado por câmaras de televisão, no interior da sua residência, vestindo pijamas e sendo algemado, ao amanhecer. ${ }^{11}$

São inúmeros os casos em que suspeitos são submetidos a constrangimento público e humilhação pelos meios de comunicação, por vezes até a tratamento degradante, tudo sob um olhar paralisado, submisso e sedento pela tragédia. No ano de 2012, a TV Bandeirantes Bahia, no Programa Brasil Urgente, em reportagem intitulada "Chororô na delegacia", expôs um jovem detido por suposta prática de estupro à situação vexatória. Ele foi entrevistado pela repórter e alegou inocência. Devido ao seu baixo grau de instrução, confundiu "exame de próstata" com "exame de corpo de delito", afirmando desejar realizar tal exame para provar

11 V. LEITÃO, Helio. O Pijama do Pitta. Ordem dos Advogados do Brasil. Conselho Federal. Brasília, [2008]. Disponível em: <http://www.oab.org.br/noticia/14552/artigo-o-pijama-do-pitta>. Acesso em: 27/11/2016. Nesse sentido, afirmou o Presidente da OAB/CE na época dos fatos: “... já não se consegue enxergar interesse público em ver o ex-prefeito de São Paulo Celso Pitta, ainda sonolento e de pijamas, ser preso e algemado em frente às câmeras de televisão. Trata-se, isto sim, de um desserviço, uma agressão às garantias constitucionais do cidadão. Mesmo àqueles acusados de crimes. Há de se ter coragem cívica para, em meio ao aplauso geral, ponderar sobre a espetaculosidade e abusos que têm caracterizado algumas operações policiais. Exposição da imagem de investigados à execração pública e o desvirtuamento do uso de algemas são práticas a merecer repúdio, necessitando de urgente disciplinamento". Sobre esse mesmo episódio, a Associação dos Juízes Federais de São Paulo e Mato Grosso do Sul (AJUFESP) publicou nota repudiando a divulgação das imagens e classificando a prática como de violência aos direitos e garantias fundamentais. Cf. VAZAMENTO de dados: Ajufesp critica vazamento de informações na Operação Satiagraha. Consultor Jurídico, 8 de julho de 2008. Disponível em: <http://www.conjur.com. br/2008-jul-08/ajufesp_critica_atuacao_pf_operacao_satiagraha>. Acesso em: 10/10/2016. 
não ter praticado o crime. A repórter debochou da situação e pediu muitas vezes para o suspeito repetir o nome do exame a fim de fazer chacota. O vídeo foi disponibilizado no youtube ${ }^{12}$ pela própria emissora e obteve grande repercussão negativa nas redes sociais. Diferentemente do imaginado pela emissora e pela repórter, houve inúmeras manifestações de repúdio à reportagem, o que culminou com a condenação de ambos por "dano moral coletivo" em ação civil pública movida pelo Ministério Público. Além dos atos praticados pela repórter, a sentença também considerou a fala do apresentador do Programa que chamou o mero suspeito de "estuprador". Os autores da ação objetivavam também a proibição de entrevista e exposição das imagens de presos, mas essa parte do pedido foi julgado improcedente, tendo por fundamento a liberdade de imprensa. ${ }^{13}$

Isso tudo após a sociedade brasileira já ter passado pela experiência do "Caso Escola Base", que é considerado um case de estudos sobre os danos que a divulgação apressada de informações policiais ou judiciais pode trazer ao estado de inocência. Esse caso também sensibiliza porque restou provada a inocência dos suspeitos (o que raramente se consegue em matéria penal), os quais tiveram suas reputações e estilos de vida totalmente alterados por essa danosa ação. ${ }^{14}$ Ressalta-se, todavia, que o direito ao estado de inocência é elemento do direito ao justo processo, aplicável a todos os casos em andamento, sendo passível a responsabilização dos violadores, ainda que o réu reste condenado. $O$ direito ao justo processo é autônomo, independente do resultado final do processo.

A exibição do preso, sob custódia do Estado, ganha maior repercussão quando divulgado na internet porque, além de atingir um grande número de pessoas, concomitante aos acontecimentos, sem delimitação territorial e permanecer na rede ad eternum, permite a colaboração dos internautas por meio de opiniões e compartilhamento de mensagens, potencializando o alcance, dispersando e, paradoxalmente, concentrando a notícia. A divulgação imediata da reportagem, enquanto a investigação ainda está em andamento e a postagem na rede instantaneamente aos acontecimentos, écaracterística da sociedade da informação.

A adesão a redes sociais como Facebook e outras permite a dispersão da notícia 12 Disponível em: <https://www.youtube.com/watch?v=1lk0yMCCWso>. Acesso em: 10/10/2016.

13 Disponível em: <https://portal.trf1.jus.br/sjba/comunicacao-social/imprensa/noticias/11-vara-condenaradio-e-televisao-bandeirantes-por-dano-moral-coletivo.htm>. Acesso em: 10/10/2016.

14 Disponível em: <https://www.youtube.com/watch?v=vGRIuXESqco>. Acesso em: 27/11/2016. 
em progressão geométrica e privilegia uma espécie de "estética da ostentação", cujo excesso de visibilidade e de exposição é, praticamente, um valor. Nesse ambiente, a apreensão da hipótese acusatória é criadora de "verdades imediatas" inconciliáveis com o tempo de construção dialética da verdade processual, único modo legítimo para afastar o estado de inocência. Essa avaliação prematura do caso penal promove um julgamento público extrajudicial, propiciando um trial by media, que afeta a dignidade da pessoa, atribuindo-Ihe etiquetas sociais de difícil ou impossível reparação.

Na realidade empírica, isso faz triunfar a "verdade dada", criando expectativas gerais sobre a condenação do acusado. Como toda expectativa reclama preenchimento, ${ }^{15}$ as ferramentas da sociedade de informação serão utilizadas também com esse objetivo e para essa função - preencher expectativas de punição, sendo capazes de converter em "verdade" o que é apenas percepção e significação. No âmbito da comunicação, sobretudo do jornalismo, a busca da verdade, assim como no processo penal, exige técnicas e métodos com gradações de reflexões. Na sociedade da informação, mormente em um cenário de ciberjornalismo, redobra o trabalho do jornalista na complexa atividade de busca da verdade. A velocidade que dirige a sociedade atual e altera a forma de estruturação do pensamento e da percepção da realidade (moldado pela tecnologia da informação) torna essa tarefa (de processamento da verdade) mais arriscada e também menos prestigiada. Privilegia-se a rapidez na divulgação das versões, ainda que equivocadas, à verificação dos fatos, confundindo-se o real e o imaginário. Nesse contexto, de aumento do risco na confiabilidade da informação, também há de aumentar a responsabilidade dos gestores da comunicação, pelo menos, daqueles que fazem da informação um produto de mercado. ${ }^{16}$

15 Em CUNHA MARTINS, Rui. O Ponto Cego do Direito: The Brazilian Lessons. Rio de Janeiro: Lumen Juris, 2010.

16 V. KARAM, Francisco José Castilhos. Alguns apontamentos e um futuro aberto: sociedade da informação e do conhecimento, convergência tecnológica, diversidade midiática e ciberjornalismo. Revista

FAMECOS: Mídia, Cultura e Tecnologia. Porto Alegre, v. 17 n. 3 p. 278-285, setembro/dezembro 2010, ao afirmar que "Os princípios profissionais, defendidos ao longo do século 20, reafirmam-se como valor moral, mas, ao mesmo tempo, sofrem determinadas e mais complexas coerções, de ordem política, econômica e cultural. Hoje, efetivamente, os conglomerados midiáticos, a mídia cruzada e as megafusões empresariais levam empresas que produzem jornalismo a considerarem tal produção apenas uma das tantas existentes em seus negócios, embora reafirmem, em seus códigos ético-deontológicos, princípios e valores inalienáveis, como verossimilhança, interesse público, isenção, pluralidade, respeito à privacidade, independência, credibilidade, exatidão.”. Disponível em: <http://revistaseletronicas. pucrs.br/ojs/index.php/revistafamecos/article/view/8195/5884>. Acesso em: 15/11/2016. 
A divulgação apressada da notícia estabelece a presunção de culpabilidade fática no meio social, além de consolidar a estigmatização do imputado como criminoso. O ponto nodal a ser desvendado é se essa presunção fática de culpabilidade atinge o âmbito normativo do estado de inocência como instituição processual constitucional democrática. Isso será analisado neste trabalho.

\section{O estado de inocência no ordenamento jurídico brasileiro}

\subsection{Estado de inocência ou presunção de não culpabilidade?}

O estado de inocência é direito fundamental de primeira dimensão. É também um direito humano. Desde 1988, o estado de inocência possui dignidade constitucional no Brasil, conforme art. 50, LVII: "ninguém será considerado culpado até o trânsito em julgado de sentença penal condenatória". O texto normativo, o qual não estampa o termo "estado de inocência", nem "presunção de inocência", acabou gerando discussão quanto à existência mesma de tal estado ou presunção, em nosso sistema ou se, em lugar dela, haveria apenas presunção de não culpabilidade penal. Entende-se que não há mais razão à polêmica. $\mathrm{A}$ escolha do constituinte foi de natureza juspolítica e o debate doutrinário voltase a critérios tecnicistas, os quais pretendem obnubilar o estado de inocência. ${ }^{17}$ Percebe-se, na doutrina que prega a distinção, a pretensão de encontrar sentido unívoco na linguagem, insistindo em buscar garantia epistemológica no rigor semântico. Ocorre ser a historicidade um elemento importante no direito penal, cuja compreensão material dela não se divorcia. Atinando a isso, reconhece-se na Constituição Federal a equivalência entre "presunção de não culpabilidade penal" e "presunção de inocência", embora se prefira empregar a expressão "estado de inocência", por ser um estado inerente ao ser humano. Distinguir as expressões "presunção de inocência" de "presunção de não culpabilidade" é o mesmo que igualar texto e norma. Por isso, na esteira de Giacomolli, prefere-se utilizar a expressão "estado de inocência".

A fundamentação da distinção é, em geral, buscada no texto constitucional italiano de 1948 que prevê no artigo 27.2: "L'imputato non è considerato colpevole

17 V. MORAES, Maurício Zanoide de. Presunção de Inocência no Processo Penal Brasileiro: análise de sua estrutura normativa para a elaboração legislativa e para a decisão judicial. Rio de Janeiro: Lumen Juris, 2010, p. 215. 
sino alla condanna definitiva", cujo texto seguiu a tradição da Escola TécnicoJurídica italiana com o objetivo de conciliar ideologias opostas, a fascista, ainda forte na Península, mesmo no pós-guerra, e a democrática. A ideia de presunção de não culpabilidade como diversa de presunção de inocência foi uma criação do fascismo, baseada em critérios positivistas para negar, tecnicamente, a possibilidade de alguém ser considerado inocente até que o Estado prove a sua culpabilidade. $O$ argumento central foi de que se não era possível reconhecer culpa ao imputado, já no início da persecução penal, tampouco se poderia sustentar ser ele inocente. Assim, o texto constitucional italiano foi obtido por meio de acordo entre ideologias contrárias. ${ }^{18}$

Foram a doutrina e a jurisprudência italianas que, posteriormente, trataram de equiparar presunção de não culpabilidade com presunção de inocência, baseadas nas normas dos tratados internacionais de direitos humanos. A opção foi pela segunda expressão. A tarefa da doutrina foi eliminar da norma italiana o conteúdo ideológico fascista e fazer preponderar o democrático. Não há mais espaço para interpretação do Direito italiano em consonância com preceitos fascistas. Por isso, mesmo na Itália, os termos são tratados, atualmente, como equivalentes. ${ }^{19}$

A Constituição Federal de 1988 é fruto de intensa e longa luta pela (re) democratização do país. Antes dela, o estado de inocência não contava com previsão constitucional no Brasil. Desde a primeira proposta de redação apresentada à Assembleia Nacional Constituinte pela Comissão Afonso Arinos usava-se a palavra "inocência". Diversas emendas posteriores a mantiveram. A primeira sugestão de alteração veio com a Emenda $n^{\circ} 1 \mathrm{P} 1198-7$ de autoria do Senador Constituinte José Ignácio Ferreira (PMDB/ES) que, embora tenha mudado a forma do texto, não aderiu ao conteúdo juspolítico fascista. Assim, foram substituídos os termos (texto normativo) e mantido o conteúdo material dos trabalhos constituintes (norma). ${ }^{20} \mathrm{~A}$ distinção se tornou inútil na Itália ${ }^{21} \mathrm{e}$, no

18 Em MORAES, Maurício Zanoide de. Presunção de Inocência no Processo Penal Brasileiro: análise de sua estrutura normativa para a elaboração legislativa e para a decisão judicial, p. 215 e ss.

19 Em ILLUMINATI, Giulio. La presunzione d' innocenza dell' imputato. 6. ed. Bologna: Zanichelli. 1984, p. 29.

20 Em MORAES, Maurício Zanoide de. Presunção de Inocência no Processo Penal Brasileiro: análise de sua estrutura normativa para a elaboração legislativa e para a decisão judicial, p. 218 e 219.

21 Em ILLUMINATI, Giulio. La presunzione d' innocenza dell' imputato, p. 29. Carnelutti também defende que a "presunção de inocência" é garantida na Constituição Italiana. V. também CARNELUTTI. Principi del processo penale. Nápoli: Morano, 1960, p. 245. 
Brasil, são "variações semânticas de um mesmo conteúdo". ${ }^{22}$

As fórmulas "presunção de inocência" (formulação positiva) e "presunção de não culpabilidade" (formulação negativa) são equivalentes, independentemente das possíveis distinções idiomáticas, semânticas e de purificação conceitual. Distinguir é reduzir o alcance da regra humanitária do status libertis, afastando-se do conteúdo da previsão constante nos diplomas internacionais. Diferenciá-las é afastar o estado de inocência; é partir da culpabilidade e não da inocência. Também não há um estado de "semi-inocente". O conteúdo das expressões não pode gerar dúvidas acerca do estado de inocência, nem desvirtuar o regramento probatório, a proteção da liberdade e o tratamento do ser humano como sujeito. ${ }^{23}$

Reforça-se esta tese com a constatação de que os principais documentos internacionais de proteção dos direitos humanos preveem a "presunção de inocência". Por exemplo: a) art. 11 da Declaração Universal dos Direitos do Homem (1948); b) art. 6.2, Convenção Europeia de Direitos Humanos e Liberdades Fundamentais (1950); c) art. 14.2, do Pacto Internacional de Direitos Civis e Políticos (1966); d) art. 8.2, do Pacto de São José da Costa Rica (1969); e) art. 66.1, do Estatuto de Roma (1998); f) art. 7.b, da Carta Africana de Direitos dos Homens e dos Povos (1981); g) art. 48 da Carta de Direitos Fundamentais da União Europeia (2000). O Brasil introduziu a Convenção Americana de Direitos Humanos no seu ordenamento interno em 1992, por meio do Decreto 678, e o Pacto Internacional de Direitos Civis e Políticos, por meio do Decreto 592, no mesmo ano. Sendo assim, o estado de inocência integra o ordenamento jurídico brasileiro.

\subsection{Natureza, finalidade, estrutura normativa e modos de manifestação}

O estado de inocência, majoritariamente tratado como presunção de inocência, consiste no direito de o suspeito, investigado, réu, preso ou processado não ser considerado culpado até o trânsito em julgado de decisão judicial condenatória. Da perspectiva de que as expressões "não culpabilidade penal" e "presunção de

22 V. BADARÓ, Gustavo Henrique Righi Ivahy. Ônus da Prova no Processo Penal. São Paulo: RT, 2003, p. 282. No mesmo sentido: GOMES FILHO, Antonio Magalhaes. Presunção de Inocência e Prisão Cautelar. São PauIo: Saraiva, 1991. GIACOMOLLI, Nereu José. O Devido Processo Penal: abordagem conforme a Constituição Federal e o Pacto de São José da Costa Rica. São Paulo: Atlas/GEN, 2016.

23 Em GIACOMOLLI, Nereu José. O Devido Processo Penal: abordagem conforme a Constituição Federal e o Pacto de São José da Costa Rica, p. 119. 
inocência" são equivalentes, tem-se que a não culpabilidade, aqui, refere-se à ausência de censura criminal na conduta, não devendo ser confundida com os elementos normativos do tipo negligência, imprudência e imperícia. ${ }^{24}$ Trata-se de um conceito jurídico de culpabilidade e não em um conceito operacional de culpabilidade fática que é seu oposto. Aquele não admite a equiparação entre direitos e garantias do imputado e o poder do Estado de repressão ao delito. ${ }^{25} \mathrm{O}$ imputado, como regra, é o hipossuficiente no processo processual. ${ }^{26}$

O estado de inocência é direito fundamental com estrutura normativa de princípio; um princípio-garantia, cuja funcionalidade é proteger o status libertatis. Tratase de princípio-garantia reitor do processo penal; é o próprio fundamento do processo penal. Na perspectiva de direito de defesa, exige, em regra, atitude de abstenção do Estado no espaço de liberdades do indivíduo. Também pode exigir abstenções de particulares, como será abordado mais adiante. Possui eficácia imediata e plena nos termos do art. $5^{\circ}$, LVII, $\S 1^{\circ}$, da Constituição Federal. 0 estado de inocência se manifesta, basicamente, de dois modos autônomos, mas inter-relacionados: norma de julgamento e de tratamento. ${ }^{27}$

Como norma de julgamento exige prova incriminadora suficiente a um juízo condenatório. Quando a prova não for insuficiente à configuração de todos os elementos da conduta criminosa, prevalece o estado de inocência, o qual somente será afastado ao final do processo, ${ }^{28}$ após efetivo contraditório - argumentativo e probatório, realizado em um processo público, perante um juiz imparcial, em igualdade de condições entre as partes, cabendo à acusação o ônus probatório. A prova há de ser incriminadora e suficiente à constituição de um veredicto condenatório. Havendo dúvida, o juiz há de aplicar a regra do in dubio pro reo, emitindo um juízo absolutório.

24 V. GIACOMOLLI, Nereu José. O Devido Processo Penal: abordagem conforme a Constituição Federal e o Pacto de São José da Costa Rica, p. 119.

25 V. PRADO, Geraldo. "O trânsito em julgado da decisão condenatória", em Boletim IBCCRIM, Ano 23, $n^{\circ} 277$, p. 11.

26 Em FERRAJOLI. Luigi. Derecho y Razón: teoria del garantismo penal. Madrid: Trotta, 1999.

27 Segundo, ZANOIDE, Maurício de. Presunção de Inocência no Processo Penal Brasileiro: análise de sua estrutura normativa para a elaboração legislativa e para a decisão judicial, p. 426, além das manifestações como "norma de tratamento" e de "norma de julgamento", o princípio se manifesta também como "norma probatória".

28 No HC 126.292, de 17.2.2016, por maioria, o STF alterou o seu entendimento e passou a admitir a execução da pena antes do trânsito em julgado da sentença penal condenatória, após julgamento pelo Tribunal de segundo grau, desvirtuando o conteúdo e a funcionalidade do art. $5^{\circ}$, LVII, CF. Tal entendimento foi reafirmado, por maioria, nas ADCs 43 e 44, de 2016. 
Como norma de tratamento, o estado de inocência exige que a pessoa seja tratada como inocente durante toda a persecução penal, até que advenha sentença penal condenatória transitada em julgado. Aplica-se às fases préprocessual e processual, em todas as instâncias, até a declaração de trânsito em julgado para o réu ${ }^{29}$. Impõe-se também ao legislador ordinário que não pode elaborar leis que venham a eliminá-la ou restringir sua eficácia e, se o fizer, devem ser declaradas inconstitucionais ou inconvencionais - neste último caso se não restarem aprovadas pelo Controle de Convencionalidade. ${ }^{30}$ Como o Código é produto da ditadura do Estado Novo, cujo modelo adotado foi o do Código Rocco da Itália, de orientação fascista, os juízes devem, no caso concreto, dar aos dispositivos legais uma interpretação conforme a Constituição Federal, de modo a considerá-los não recepcionados, conforme o caso, para garantir efetividade ao estado de inocência.

Situação bastante corriqueira refere-se à divulgação do caso penal pelos meios de comunicação em circunstâncias que estigmatizam o imputado, sem decisão condenatória, mesmo antes de ser julgado por Tribunal. ${ }^{31}$ Essa forma específica de violação ao estado de inocência, como norma de tratamento, será analisada mais adiante. $O$ estado de inocência é direito humano previsto em documentos internacionais aos quais o Brasil aderiu. Ele integra o direito ao justo processo ou ao fair trial. Luiz Guilherme Marinoni, ao tratar sobre o "direito fundamental ao processo justo" expõe que ele se constitui pela soma de todos os demais direitos fundamentais que o compõem. Por isso, violado um dos direitos fundamentais que constituem o fair trial, o que "representa o jus commune em matéria processual" terá sido violado. Trata-se de "um modelo mínimo de conformação do processo", 32 estabelecido internacionalmente, por consenso político e jurídico

29 V. nota supra, acerca do entendimento atual do STF, permitindo a execução provisória do julgado, mesmo quando ainda possíveis os recursos aos Tribunais Superiores.

30 V. SARLET, Ingo Wolfgang. Notas sobre as relações entre a Constituição Federal de 1988 e os Tratados Internacionais de Direitos Humanos na perspectiva do assim chamado Controle de Convencionalidade. In: MARINONI, Luiz Guilherme; MAZZUOLI, Valerio de Oliveira. Controle de Convencionalidade: um panorama latino-americano. Brasília: Gazeta Jurídica, 2013.

31 Em GIACOMOLLI, Nereu José. O Devido Processo Penal: abordagem conforme a Constituição Federal e o Pacto de São José da Costa Rica, p. 125. V. LOPES Jr. Direito Processual Penal. São Paulo: Saraiva, 2013, p. 230 e SCHREIBER, Simone em entrevista ao CONJUR. Disponível em: <http://www.conjur.com.br/2008-jun-29/ liberdade_expressao_nao_direito_absoluto $>$. Acesso em: 20/11/2016. Ver também: O princípio da presunção de Inocência. Instituto dos Advogados do Brasil, Revista Digital, Rio de Janeiro, nº 10, p. 85 a 101, Abr-Jun. 2011. Disponível em: <http://www.iabnacional.org.br/IMG/pdf/doc-5287.pdf>. Acesso em: 08/09/2015

32 Em SARLET, Ingo Wolfgang; MARINONI, Luiz Guilherme; MITIDIERO, Daniel. Curso de Direito Constitucional. 
entre os povos, emanado da experiência concreta da arbitrariedade.

O estado de inocência é fundamento de todas as demais garantias processuais e, por isso, é requisito dos regimes democráticos, no entendimento da Corte Interamericana de Direitos Humanos (Caso Tibi vs. Equador - 2004). "As garantias processuais se estruturam em torno da inocência, que não impede a persecução penal, mas a racionaliza" (voto do juiz Sérgio García Ramírez). O estado de inocência é constitutivo do processo penal justo; é seu próprio fundamento. Desse modo, violado o estado de inocência, violado estará o justo processo, previsto no art. $8^{\circ}$ da Convenção Americana de Direitos Humanos.

O princípio-garantia do estado de inocência possui conteúdo endoprocessual e extraprocessual. ${ }^{33}$ Aquele direcionado aos agentes do Estado para proteger o imputado (suspeito, acusado ou réu), o qual deve ser tratado como sujeito de direitos e não como objeto do processo. Já o efeito extraprocessual destinase a todos os cidadãos em todas as suas relações, bem como aos agentes do Estado, inclusive legislador ordinário. Note-se que a publicidade abusiva pode afetar o conteúdo extraprocessual do estado de inocência como norma de tratamento, mas também pode afetá-lo como regra de julgamento, conteúdo endoprocessual, já que pode influenciar a percepção do julgador, antecipando seu convencimento, ainda que de modo inconsciente, antes do contraditório, em prejuízo do réu. Isso poderá ocorrer, sobretudo, nos casos submetidos ao Tribunal do Júri, onde não há possibilidade de controle intersubjetivo mediante fundamentação da decisão.

Segundo Timothy Otty, o direito à presunção de inocência pode ser compreendido por cinco características principais: a) exige que os julgadores não tenham, e também não aparentem ter, qualquer ideia preconcebida de que o imputado praticou o crime do qual é acusado; b) não possui como destinatário apenas os juízes que atuam no processo, mas também todos os demais órgãos estatais e agentes públicos; c) comentários desfavoráveis ao caso ou ao imputado na imprensa podem afetar, de modo prejudicial, a justiça do julgamento e, ainda, levar à conclusão de que o direito a ser presumido inocente foi violado, independente

2. ed. São Paulo: Revista dos Tribunais, 2013, p. 699, 701 e 702.

33 Segundo o STF, na ADPF 144 e na SL 936, de 20.5.2016, o estado de inocência produz seus efeitos no interior do processo e também fora dele. 
do resultado final do processo; d) os investigadores atuantes na fase préprocessual não devem afirmar a prática do crime com base em preconceitos sobre os acusados, pois o direito a um justo processo aplica-se também às fases anteriores à processual; e) mesmo que a instância superior possa corrigir violações à presunção de inocência, mediante absolvição ou extinção do processo, haverá casos em que isso não será suficiente para remediar os danos causados, como ocorre quando um pessoa ou uma empresa tem sua reputação e estilo de vida irremediavelmente prejudicada por coberturas jornalísticas. ${ }^{34}$ Nota-se, pois, que há certo consenso doutrinário de que exposição midiática de imputado ainda não condenados viola o estado de inocência.

\section{Cases do Tribunal Europeu de Direitos Humanos (TEDH)}

O TEDH vem decidindo pela violação do estado de inocência como norma de tratamento, quando o imputado não é tratado como inocente quando deveria, seja dentro ou fora do processo, como demonstram os casos a seguir, escolhidos de modo aleatório. ${ }^{35}$

No Case Lavents vs. Letonia (2002), o TEDH reconheceu a violação do art. 6.2, da Convenção Europeia de Direitos Humanos e Liberdades fundamentais, o qual garante o estado de inocência, porque uma juíza do caso afirmou, em entrevista, antes do encerramento do processo, que ela não havia decidido se iria condenar ou absolver parcialmente o acusado. Entendeu-se que essa manifestação sugeria que, no entender da julgadora, caberia ao imputado provar sua inocência para mudar sua convicção. Houve também manifestações públicas do Primeiro Ministro e do Ministro da Justiça, tecendo críticas à condução do processo, o que culminou com a renúncia do conselho de sentença, fundamentada em "pressão do governo e do público". Posteriormente, uma juíza substituta fez diversas afirmações criticando a conduta da defesa e se referindo ao resultado final do processo. A magistrada, ainda, manifestou surpresa pelo fato de o acusado persistir negando as acusações e o interpelando para provar sua inocência. Contata-se que os fatos

34 QC, Timothy Otty. "The presumption of innocence and the right to a fair trial in international law". Boletim IBCCRIM, ano 23, n² 277, dezembro/2015, p. 25 e 26.

35 Além dos casos analisados no texto, outros poderiam ser referenciados, tais como o Caso Butkevicius vs. Lituânia (2002), Caso Y.B. vs. Turquia (2004); Caso Ismoilov vs. Rússia (2008). 
centrais que embasaram a decisão foram as declarações feitas na imprensa por autoridades públicas.

Conforme o Case Allenet vs. França (1995), o Estado foi condenado, porque o investigado foi descrito por policiais como sendo "o instigador" do crime sob investigação, ou seja, foi tratado como se fosse criminoso e não como inocente, enquanto assim deveria ter sido. A França argumentou que o estado de inocência previsto no art. 6.2 da Convenção destina-se apenas às autoridades judiciais. A Corte entendeu que esse direito humano é oponível a qualquer agente público.

No Case Konsas vs. Grécia (2001), o Tribunal Europeu decidiu que a Convenção é violada quando, ainda pendente recurso, Ministros de Estado, incluindo o da Justiça, fazem pronunciamentos no Parlamento chamando os acusados de "vigaristas". Essa conduta teria violado o estado de inocência, restando destacado que observações ofensivas aos acusados exigem discrição e impõem restrições, em especial para o Ministro da Justiça. Observa-se que manifestações públicas sobre o caso, ainda que fora do processo, podem violar a presunção de inocência (estado de inocência), segundo decisões do TEDH.

\section{Cases na Corte Interamericana de Direitos Humanos}

O Tribunal de São José da Costa Rica considera violado o estado de inocência quando o imputado for tratado como culpado, por autoridades públicas, perante os veículos de comunicação. ${ }^{36}$ No Case Cantoral Benavides vs. Peru (2000), a Corte Interamericana julgou violado o estado de inocência previsto no art. 8.2 da $\mathrm{CADH}$ - como regra de julgamento - porque os juízes presumiram a culpa do réu desde o início do processo, deixando para ele o ônus de provar a inocência. A Corte das Américas julgou também violado o direito - como norma de tratamento, porque o acusado foi exposto perante os veículos de comunicação, como detido, sob custódia do Estado, vestindo uniforme de presidiário. Essa situação teria potencial para firmar no público o entendimento de que o acusado era culpado, antes do momento processual oportuno. Deveria ser tratado como inocente dentro e fora do processo até a sentença condenatória definitiva.

36 Também poderiam ser citados outros casos da Corte Interamericana de Direitos Humanos, acerca do estado de inocência: Caso Ricardo Canese vs. Paraguai (2004); Caso Tibi vs. Equador (2004); Caso López Mendoza vs. Venezuela (2011); Caso Ruaro Torres e Outros vs. El Salvador (2015). 
No Caso J. vs. Peru (2013), a Corte Interamericana responsabilizou o Estado peruano por ter "condenado informalmente" a acusada. O termo informal é aplicado em oposição à oficial porque mesmo não havendo condenação judicial emitida por órgão estatal conforme previsto em lei, houve manifestações de agentes públicos perante órgãos de imprensa, emitindo opinião sobre o caso e a pessoa da acusada, "condenando-lhe" perante a opinião pública, antes do momento processual adequado ao reconhecimento de sua culpabilidade penal. Além disso, a Senhora J. teve sua imagem exposta perante veículos de comunicação, em uma entrevista coletiva dada pelo Ministro do Interior. Nessa, foi cunhada de "terrorista" e "senderista" (como se chamam os membros do grupo armado Sendero Luminoso), sem que fossem feitas quaisquer ressalvas para resguardar o estado de inocência, tendo em vista que ainda não havia sido julgada pelo delito de que estava sendo acusada. Houve também reprodução de tal entrevista em jornais e revistas. A Corte afirmou que a entrevista fez com que os meios de comunicação entendessem que a Senhora J. era "uma terrorista" sem qualquer reserva de tratar-se de mera suspeita e sem contextualização dos fatos e das acusações. Além desse episódio, protagonizado pelo Ministro do Interior, anos depois, altas autoridades do Estado fizeram declarações tratando a Senhora J. como "membro do Sendero Luminoso". Para a Corte, a apresentação da investigada pelos jornais, como membro do grupo armado, assim como as declarações de distintos servidores públicos, em diversos momentos, sem reservas ou contextualização, fomentaram a crença na sociedade sobre a culpabilidade da acusada, quando ainda não havia sido condenada pelos delitos de que era acusada em violação do art. 8.2 da Convenção.

O que se percebe nesse julgado é que a Corte valorizou as circunstâncias de que as autoridades não fizeram qualquer referência ao fato de que a Senhora J. era mera suspeita ou que deveria ser considerada inocente até o encerramento do processo. Ao contrário, foi tratada como criminosa, como se a culpabilidade jurídica já fosse conhecida desde então. Não parece que a divulgação do caso em si tenha motivado a responsabilização do Peru, mas o fato de ter ocorrido "sem reservas". Nota-se que a Corte considerou a importância de as declarações terem sido pronunciadas por agentes estatais, o que, em nosso entender, passa a ideia 
de oficialidade da informação em uma espécie de presunção de veracidade. A Corte também considerou que a repercussão midiática poderia influenciar os julgadores.

Merece destacar que, nessa mesma decisão, a Corte Interamericana também considerou violado o princípio da publicidade processual, previsto no art. 8.5, do Pacto de São José da Costa Rica, porque a primeira etapa do processo transcorreu em sigilo. Entendeu-se que a publicidade deve ser a regra geral e que o sigilo somente pode ser aplicado em casos especiais, no interesse da Justiça. A Corte destacou que a publicidade exigida pelo art. 8.5 é uma garantia do acusado e elemento essencial de um sistema acusatório em um Estado democrático. ${ }^{37}$ Observa-se, portanto, que não se pode confundir publicidade do processo, o que é uma garantia processual prevista tanto na Constituição brasileira quanto na $\mathrm{CADH}$, com a publicização, geralmente orientada por uma "estética do espetáculo", que é violadora de direitos fundamentais e de direitos humanos. ${ }^{38}$

As decisões da Corte Interamericana de Direitos Humanos devem ser observadas pela jurisdição brasileira, a quem cabe interpretar e aplicar as regras da Convenção Americana de Direitos Humanos, de modo que sua inobservância pode levar à condenação internacional do Brasil por violação do direito humano ao estado de inocência. Nesse sentido, percebe-se que, no entendimento da Corte Interamericana, o Estado responde, internacionalmente, sempre que seja

37 "La garantía de publicidad establecida en el artículo 8.5 de la Convención es un elemento esencial del sistema procesal penal acusatorio en un Estado democrático y se garantiza a través de la realización de la etapa oral en la que el acusado pueda tener inmediación con el juez y las pruebas y que facilite el acceso al público. De esta manera se proscribe la administración de justicia secreta, sometiéndola al escrutinio de las partes y del público, relacionándose con la necesidad de transparencia e imparcialidad de las decisiones tomadas. Siendo un medio que fomenta la confianza en los tribunales de justicia. La publicidad hace referencia específica al acceso a la información del proceso que tengan las partes e incluso los terceros." Disponível em: <http://www.corteidh.or.cr/docs/casos/articulos/seriec_275_ing.pdf>. Acesso em: 28/11/2016.

38 Segundo HABERMAS, Jürgen. Mudança Estrutural da Esfera Pública: Investigação quanto a uma categoria da sociedade burguesa. Rio de Janeiro: Tempo Brasileiro, 1984, p. 242 e 243: "Os processos penais que são suficientemente interessantes para serem documentados e badalados pelos meios de comunicação de massa, invertem, de modo análogo, o princípio crítico da 'publicidade', do tornar público; ao invés de controlar o exercício da justiça por meio dos cidadãos reunidos, serve cada vez mais para preparar processos trabalhados judicialmente para a cultura de massas dos consumidores arrebanhados. (...) não se trata de interditar o livre acesso aos debates, mas deve-se impedir que a partir de um processo penal se faça um show processual para a diversão dos consumidores não-participantes". "o que se perde, afinal de contas, quando não se consegue ver na imprensa fotos de acusados ou testemunhas?" "pode haver um justificado interesse da esfera pública em saber de que atos são acusadas personalidades contemporâneas, o que se esclarece quanto a isso no processo e qual é a sentença. Estes são momentos importantes para formar a opinião dos cidadãos interessados na vida pública e que, através de um confiável relato sobre o processo, também podem ser levados ao conhecimento de quem não participa das negociações. Mas qual a expressão fisionômica do acusado e das testemunhas durante a audiência principal, os interrogatórios e o veredicto, e algo completamente indiferente a todo interesse justo". 
por pronunciamento de seus agentes, seja por exposição do imputado na mídia, reste sugerido ao público, antes do momento autorizado por lei que ele seja culpado. O Estado possui a obrigação internacional de conferir ao imputado tratamento de inocente dentro e fora do processo e de coibir toda manifestação de agentes do Estado, servidores públicos, que adentre de modo ilegítimo no espaço normativo da presunção de inocência como norma de tratamento. Em nosso entender, a responsabilidade do Estado é sempre objetiva. Outra hipótese de responsabilização do Estado é quando o imputado tem sua imagem apresentada como se sua culpabilidade já estivesse determinada, ainda que nada seja dito nesse sentido. É o que ocorre quando um acusado aparece vestindo uniforme de presidiário ou algemado perante as câmaras de televisão. Nesta situação, o Estado detém seu corpo e é responsável por tudo o que acontecer com ele em tal situação. Se a pessoa é filmada quando está em poder da polícia, por exemplo, o Estado possui responsabilidade pela filmagem e pela divulgação. O Estado há de zelar para que o estado de inocência, inclusive no seu conteúdo extraprocessual, seja preservado. ${ }^{39}$

\section{Particulares como destinatários do estado de inocência: vinculação ou não dos órgãos de imprensa}

A abordagem aqui feita refere-se, exclusivamente, às relações entre os media (pessoas físicas ou jurídicas) e particulares, no que toca à divulgação de informações sobre processos penais ou procedimentos de investigação em andamento. O objeto de análise empreendido não engloba a prática de atos por particulares que não estejam vinculados a ações profissionais de media. O que

39 Também poderia ser citado, como case do STF, o Caso das Algemas. Como se pode inferir da Súmula Vinculante $n^{\circ} 11$ do Supremo Tribunal Federal, o problema não está em algemar em si, mas o de mostrar o preso algemado diante dos órgãos de imprensa. Parece-nos que, ainda que sem enfrentar sob esse aspecto, o STF percebeu violado o estado de inocência, como norma de tratamento, em hipóteses tais. A Suprema Corte decidiu ser necessária à emissão da Súmula vinculante $n^{\circ} 11$, em decorrência de precedentes, dentre eles o julgamento do Habeas Corpus 91.952, no qual se buscava a anulação de um julgamento condenatório proferido pelo Tribunal do Júri, porque o réu permaneceu algemado durante toda a sessão, o que teria sugestionado os jurados, em prejuízo da defesa. O Supremo Tribunal Federal entendeu, sem dizer desse modo, que as algemas consistem em um símbolo capaz de interferir na percepção julgadora de pessoas comuns, como os jurados. Talvez, e isso é mera especulação nossa, o STF desejasse proibir a exibição do preso perante os veículos de comunicação, mas, ciente das dificuldades de impedir isso, sobretudo em razão da liberdade de imprensa, tenha optado, em uma lógica pragmática, em proibir a colocação de algemas em si. A Súmula Vinculante $\mathrm{n}^{\circ} 11$ veio, então, como meio de garantia do conteúdo extraprocessual do estado de inocência manifestado como norma de tratamento. 
importa, aqui, são notícias divulgadas pelos meios de comunicação, como rádio, televisão, material textual de jornalismo, incluindo os textos da internet, como blogs e páginas de notícias na web, o ciberjornalismo, voltados à divulgação da informação ao público em geral, como atividade comercial ou profissional. Não se ocupem de manifestações de indivíduos, por exemplo, no Facebook ou no Twitter, as quais, embora possam ser acessíveis a um número ilimitado de pessoas, em todo o mundo, e possam causar danos a terceiros, não são fontes de "poder social".

É que, no que tange à vinculação dos particulares a direitos fundamentais como ao estado de inocência, sempre haverá, em contraposição, o direito, também fundamental, à liberdade de expressão. Os destinatários de um serão titulares do outro e vice-versa. É demais temerário interferir na liberdade de expressão, porque essencial a qualquer democracia. Corre-se o risco de cair em moralismos sectários, inadmissíveis em uma sociedade plural. Por essa razão, entende-se que notícias lançadas na rede por particulares devem ser tratadas no âmbito do direito à honra com justa indenização, sem adentrar no espaço do estado de inocência. Não há, pelo que se pesquisou até agora, meios jurídicos de impor o estado de inocência a qualquer particular. Contudo, entende-se que os veículos de comunicação de massa estão vinculados não só ao direito fundamental à honra, mas também ao direito fundamental ao estado de inocência, de forma autônoma. Isso porque se enquadram no conceito de "poder social", que se caracterizam por possuir "poder" de que a outra parte não dispõe, por gozar de supremacia perante o outro, que desequilibra a relação jurídica.

A teoria da submissão de particulares aos direitos fundamentais divide-se em diferentes posições, as quais não serão aqui analisadas por limitação de espaço. Tais divergências doutrinárias não se voltam à possibilidade ou não de vinculação dos direitos fundamentais aos particulares, já que há consenso neste sentido. A discussão tende a derivar à forma como se dá esta vinculação e sua intensidade. É preciso dizer que, em geral, considera-se que as garantias fundamentais processuais penais, em princípio, não podem ser opostas a particulares, tendo exclusivamente o Poder Público como destinatário. ${ }^{40}$ Essa 40 V. SARLET, Ingo Wolfgang. Direitos Fundamentais e Direito Privado: algumas considerações em torno da vinculação dos particulares aos direitos fundamentais. In: SARLET, Ingo Wolfgang. A Constituição Concretizada. Porto 
posição é compreensível, na medida em que o estado de inocência constitui direito de defesa, exigindo uma atuação negativa e pressupõe o poder de punir do Estado. A aplicação da pena é monopólio estatal e somente será legítima se aplicada no âmbito de um processo jurisdicional que conceda ao acusado todos os direitos e as garantias previstos na legislação em geral, na Constituição e nos tratados internacionais de direitos humanos. Contra abusos desse poder de julgar e punir é que existem os direitos fundamentais processuais como o estado de inocência. Este, como dito, impõe que o réu seja tratado como inocente até decisão final que declare sua culpabilidade. A decisão condenatória tem como pressuposto a certeza da materialidade e da autoria do crime, assim como da presença de todos os seus elementos constitutivos. Essa certeza do juiz advém do material probatório, produzido em contraditório, sob o comando do Estado. Os particulares não podem, validamente, aplicar penas, nem conduzir processos penais. Daí, perfeitamente compreensível que direitos dessa espécie, em geral, somente possam ser oponíveis ao Poder Público, assim como os direitos políticos, já que somente o Estado pode ser causador direto da violação.

Como é consenso na doutrina, não há como se elaborar uma teoria geral aplicável, sem exceções, a todos e a cada um dos direitos fundamentais. Não se pode apresentar, com segurança e seriedade, soluções uniformes para todos os distintos direitos fundamentais, até porque a posição peculiar de cada particular, em cada contexto, exige que sua eficácia seja aferida no caso concreto. ${ }^{41}$ Assim, à primeira vista, parece que o direito fundamental ao estado de inocência somente pode ser oponível ao Estado. No entanto, após uma compreensão analítica das suas diferentes formas de manifestações, percebe-se que esse direito fundamental, embora de natureza processual, pode ser oposto também aos particulares, desde que detentores de "poder social", ${ }^{42}$ quanto a sua faceta de "norma de tratamento". Não há, aparentemente, possibilidade de invocar contra particulares o direito ao estado de inocência como "norma de julgamento", já que só o Estado pode

Alegre: Livraria do Advogado, 2000, p. 115 e 116; SARLET, Ingo Wolfgang. A Eficácia dos Direitos Fundamentais. Porto Alegre: Livraria do Advogado, 2015, 393 e 394; SARLET, Ingo Wolfgang. Direitos Fundamentais e Direito Privado: algumas considerações em torno da vinculação dos particulares aos direitos fundamentais, p. 117 e 118.

41 V. SARLET, Ingo Wolfgang. A Eficácia dos Direitos Fundamentais, p. 398.

42 V. SARLET, Ingo Wolfgang. Direitos Fundamentais e Direito Privado: algumas considerações em torno da vinculação dos particulares aos direitos fundamentais, p. 114, sobre o denominado "poder social". 
julgar, mas é possível invocar contra determinados particulares a observância do estado de inocência como "norma de tratamento".

Assim, se o estado de inocência impõe que o imputado seja tratado como inocente, ou seja, não pode ser tratado como culpado pelo crime, até decisão final condenatória transitada em julgado, pressupõe-se que a mídia, ao noticiar casos criminais, deve ter o cuidado de não dar a notícia como se fosse certa a culpabilidade do acusado. A divulgação indevida do caso penal na mídia é capaz de estigmatizar o imputado e reduzir significativamente seus laços sociais, assim como as possibilidades de superação dessa situação, como alternativas de emprego, por exemplo. É certo que existe liberdade de expressão e um Estado Democrático deve garanti-la e efetivá-la. Não há, portanto, como sustentar que o imputado possa pleitear que não seja divulgado o fato de ele estar sendo investigado, de que responde a um processo penal, de que eventualmente será submetido a medidas cautelares, pessoais ou reais, ou mesmo que esteve ou está preso cautelarmente. Não se pode evitar isso. Mas é exigível da mídia que possa e deva deixar claro que o envolvido é apenas acusado, suspeito, que se trata de hipótese apresentada por apenas uma das partes, que ele é considerado inocente até condenação final.

Divulgar a situação processual ou pré-processual de um sujeito não implica violação do estado de inocência. Não é possível sustentar violação do estado de inocência ou da presunção de inocência, em razão de a mídia divulgar que alguém está sendo investigado em inquérito policial, que será ouvido por CPI, que é suspeito de integrar organização criminosa, etc., porque há liberdade de imprensa. Isso não impede que o veículo seja responsabilizado, posteriormente, em caso de divulgação abusiva, que viole a honra do imputado. O problema se apresenta em uma prática - cada vez mais corriqueira no Brasil - que consiste na divulgação de pessoas algemadas, pessoas sendo presas. Essa imagem funciona como técnicas de comunicação que fazem a população crer na certeza da culpabilidade, de modo incontestável. Exemplo disso é o que ocorre diariamente nos noticiários televisivos, são notícias como "polícia do Mato Grosso desbaratou quadrilha que falsificava medicamentos". Tem-se, aí, a imputação de dois crimes, quando o processo está apenas começando e, muitas vezes, os suspeitos não foram sequer 
indiciados. É comum ouvir "polícia desbarata quadrilha que supostamente furtava veículos". Se a relatividade da informação, com o termo "supostamente", não torna definitiva a ideia de que são culpados do furto de veículos, fica indubitável que formaram quadrilha.

A situação se agrava quando violada a privacidade das pessoas com a divulgação de diálogos obtidos por meio de interceptações telefônicas ou correspondências privadas, obtidas mediante autorização judicial em investigação criminal, o que é corriqueiro no jornalismo de massa no Brasil. Muitos desses inquéritos e processos tramitam em segredo de justiça, o que consiste em mais uma violação. Divulgam-se, apressadamente, informações cuja ilicitude vem a ser declarada posteriormente - provas ilícitas. Com exceção dos casos em que a aplicação de direitos fundamentais expressamente se destina também a pessoas privadas, como o direito à honra, no âmbito da vinculação de particulares aos direitos fundamentais, em que um particular dispõe de direito subjetivo contra outro particular para fazer valer seu direito fundamental, a doutrina tende a abordar a problemática no âmbito contratual, confrontando o direito em questão com a liberdade de contratar, sob o prisma da igualdade, em que se desenvolve a noção de eficácia horizontal, já que ambos os envolvidos são detentores de direitos fundamentais contrapostos.

Há consenso em torno da ideia de que, mesmo nas relações exclusivamente entre particulares, sendo um deles "detentor de poder social", tem-se uma relação desigual. Não há dúvida de que os veículos da grande mídia são "particulares poderosos" que superam inclusive o poder que outros particulares possuem para desiquilibrar relações contratuais, como o empregador para com o empregado. A mídia é tão poderosa que é chamada de "Quarto Poder", o qual se exerce independente de qualquer relação negocial com o atingido. A situação é diversa dos casos, geralmente, analisados. Os veículos de comunicação têm obrigação de buscar a informação mais completa possível e devem saber que o inquérito policial jamais permite concluir pela responsabilidade de alguém. Sempre o inquérito conterá uma hipótese, nada mais do que uma simples hipótese. Daí que os veículos devem divulgar a notícia tratando a culpabilidade como uma 
hipótese e não como um "fato incontroverso". Tanto que os próprios códigos de conduta dos veículos de comunicação orientam seus colaboradores no sentido da precariedade da informação contida em inquérito policial e nos riscos de uma divulgação equivocada. ${ }^{43}$

\section{Os media possuem o poder de criar ou manipular a subjetividade de todo um} grupo social. Nesse contexto, quem passa a informação está imbuído do poder de construir a história, de oficializar versões, de formar opinião, ${ }^{44}$ de formar juízos, de definir destinos sociais, de lesar vidas humanas em razão do "poder social" que exercem. Esse poder, cada vez maior, que os meios de comunicação de massa detêm deve ter como equivalente um dever de respeitar a dignidade da pessoa, de contribuir para uma sociedade justa e solidária, pautada no respeito ao próximo e aos fins do Direito. Por isso, a eficácia do direito fundamental ao

43 Como exemplo, tem-se o Manual de Redação e Estilo do jornal o Estado de São Paulo com a seguinte orientação: "Nunca atribua um crime a alguém, a menos que a pessoa tenha sido presa em flagrante (e não haja dúvidas a respeito da sua culpa) ou confessado o ato. Mesmo que seja a polícia quem faça a acusação, recomenda-se cautela para que o jornal, involuntariamente, não difunda uma versão que se possa demonstrar equivocada ou inverídica. Assim, a não ser nos casos notórios, refira-se sempre ao acusado nestes termos: Fulano de tal, acusado de ser o matador de... / Fulano de tal, acusado de ser o principal receptador de jóias da cidade... Nunca afirme que ele "é o matador" ou "é o principal receptador", a não ser nas hipóteses já mencionadas." Cf. MARTINS, Eduardo. O Estado de São Paulo: Manual de Redação e Estilo. 3. ed. São Paulo: O Estado de São Paulo, 1997, p. 31. Disponível em: <http://naui.ufsc.br/files/2010/09/Manual-de-Reda\%C3\%A7\%C3\%A3o-e-Estilo_O-Estadode-S\%C3\%A3o-Paulo.pdf. >. Acesso em: 27/11/2016.

44 Cf. SCHOPENHAUER, Arthur. A arte de ter razão. São Paulo: Martins Fontes, 2009, p. 43 a 45 , "O que então se chama de opinião geral é, a bem da verdade, a opinião de duas ou três pessoas; e disto nos convenceríamos se pudéssemos testemunhar como se forma tal opinião universalmente válida. Acharíamos então que foram duas ou três pessoas a supor ou apresentar e afirmar num primeiro momento, e que alguém teve a bondade de julgar que elas teriam verificado realmente a fundo tais colocações: o preconceito de que estes seriam suficientemente capazes induziu, em princípio, alguns a aceitar a mesma opinião: nestes, por sua vez, acreditaram muitos outros, aos quais a própria indolência aconselhou: melhor acreditar logo que fazer controles trabalhosos. Desse modo, dia após dia cresceu o número de tais adeptos indolentes e crédulos: pois, uma vez que a opinião já contava com uma boa quantidade de vozes do seu lado, os que se seguiram atribuíram ao fato de que ela só podia ter conquistado tais votos graças à consistência de seus fundamentos. Os que ainda restaram foram constrangidos a concordar com o que já era considerado válido por todos, a fim de não serem considerados cabeças irrequietas que se rebelam contra opiniões universalmente aceitas, nem garotos intrometidos que querem ser mais inteligentes que o mundo inteiro. A essa altura, o consenso tornou-se uma obrigação. A partir de então, os poucos que têm capacidade de julgar precisam calar, e os que podem falar são aqueles completamente incapazes de ter opinião e julgamento próprio, são o mero eco da opinião alheia: contudo são também defensores tanto mais zelosos e intransigentes dela. Pois, naquele que pensa outro modo, odeiam menos a opinião diferente que ele professa do que o atrevimento de querer julgar por conta própria, experiência que eles mesmos nunca fazem e da qual, no seu íntimo, têm consciência. Em suma, muito poucos sabem pensar, mas todos querem ter opiniões: o que mais Ihe resta a não ser, em vez de criá-las por conta própria, aceitá-las totalmente prontas de outros? Uma vez que assim sucede, quanto poderá valer a voz de cem milhões de pessoas? Tanto quanto um fato histórico que se encontra em cem historiadores, mas que depois se comprova ter sido transcrito por todos, um após o outro, motivo pelo qual, no fim das contas, tudo reflui ao depoimento de um único homem (segundo Pierre Bayle, Pensées sur les cometes [4. ed., 1704], tomo I, p. 10). Dico ego, tu dicis, sed denique dixit et ille: Dictaque post toties, nil nisi dicta vides. Não obstante, quando se discute com pessoas comuns, pode-se fazer uso da opinião geral como de uma autoridade". 
estado de inocência, em relação aos media, é vertical.

Faz-se mister, portanto, repensar as relações dos media com a sociedade. É preciso exigir deles compromisso com a cidadania e com a dignidade da pessoa humana, atuando sobre o espaço da liberdade de imprensa, se necessário, para proteger o direito fundamental ao estado de inocência. Isso deve ser feito de modo adequado e transparente. A regulação do setor, com o controle social (não estatal), talvez, possa contribuir para o avanço. Importa registrar que a quase totalidade das empresas jornalísticas no Brasil opera por concessão pública. Assim, as empresas devem se submeter à responsabilidade objetiva quando violado o estado de inocência. Responsabilidade subjetiva pode ser discutida em matéria de violação do direito à honra, porque de sua própria essência, mas não a violação ao estado de inocência. E não haveria risco demasiado à liberdade de expressão porque bastaria não chamar o suspeito de "ladrão", "assassino", etc. A simples contextualização clara da situação jurídica da pessoa, de que se trata de mera suspeita, afastaria responsabilidade sobre esse aspecto, embora possa, ainda, ensejar no âmbito do direito à honra.

Entende-se que "os direitos fundamentais atuam, em verdade, como forma de defesa contra toda e qualquer opressão, auxiliando, de tal sorte, na superação do fenômeno que oportunamente foi designado de 'neofeudalismo social', característico da moderna sociedade industrial e tecnológica" 45 e, dir-se-ia, mais ainda da "sociedade da informação". Assim, a própria Constituição deixou claro que o direito à liberdade de expressão e informação não é absoluto, como nenhum direito o é, sendo seu exercício limitado pela própria Constituição que, como os tratados internacionais de direitos humanos, tem o estado de inocência como direito fundamental.

\section{CONSIDERAÇÕES FINAIS}

O estado de inocência se constitui em um princípio-garantia de elevado potencial político e jurídico, o qual dá sustentação humanitária ao sistema criminal, tanto

45 V. SARLET, Ingo Wolfgang. Direitos Fundamentais e Direito Privado: algumas considerações em torno da vinculação dos particulares aos direitos fundamentais, p. 133. 
na perspectiva endoprocessual quanto extraprocessual. $O$ fato de estar sendo investigado ou processado não retira da pessoa a integralidade do status que Ihe confere o estado de inocência, motivo pelo qual não se admite qualquer estigmatização em face da imputação (tratamento externo). Do estado de inocência se inferem três importantes consequências jurídicas: encargo probatório da culpabilidade do acusado pela acusação; absolvição do imputado, nos casos de dúvida - in dubio pro reo; afastamento de tratamento do suspeito, do acusado e do réu, como culpado, antes de uma sentença definitiva. $O$ estado de inocência transcende ao plano abstrato e o endoprocessual, atingindo a sua efetivação também fora do processo, tendo como destinatários as entidades estatais e seus agentes, bem como os meios de comunicação e os órgãos da imprensa.

A liberdade de expressão há de ser compatibilizada com o estado de inocência, de modo a tornar destinatários também os órgãos de imprensa, embora particulares, na medida em que são fontes de "poder social" ("particulares poderosos", "quarto poder"), que se caracteriza por possuir "poder", não disponível à outra parte, ademais de gozar de supremacia frente ao outro. Prima facie, parece que o direito fundamental ao estado de inocência somente poderia ser oponível ao Estado. Contudo, na perspectiva de uma compreensão analítica de suas diferentes formas de manifestações, percebe-se que esse direito fundamental, embora de natureza processual, pode ser oposto também aos particulares, desde que detentores de "poder social", quanto à sua faceta de "norma de tratamento". Por isso, o estado de inocência não veda a divulgação da prática de um ilícito e de sua autoria, mas exige que o sujeito não seja tratado, antecipadamente, como culpado, que sejam evitadas técnicas midiáticas que representem a antecipação da tutela penal condenatória e a estigmatização pessoal, familiar e social do sujeito. Este, mesmo sendo suspeito da prática de uma infração criminal, há de ser tratado como ser humano. E o fato é apenas uma hipótese a ser confirmada no devido processo penal a posteriori.

\section{REFERÊNCIAS DAS FONTES CITADAS}

BADARÓ, Gustavo Henrique Righi Ivahy. Ônus da Prova no Processo Penal. São Paulo: RT, 2003. 
BAUMER, Franklin L. O Pensamento Europeu Moderno, v. I, Lisboa: Edições 70, 1977.

BAUMER, Franklin L. O Pensamento Europeu Moderno, v. II. Lisboa: Edições 70, 1977.

BRASIL. Presidência da República. Secretaria de Comunicação Social. Pesquisa brasileira de mídia 2015: hábitos de consumo de mídia pela população brasileira. Brasília: Secom, 2014. Disponível em: <http://www.secom.gov.br/atuacao/pesquisa/lista-de-pesquisasquantitativas-e-qualitativas-de-contratos-atuais/pesquisa-brasileira-de-midia-pbm-2015. pdf $>$. Acesso em 27/11/2016.

CARNELUTTI. Principi del processo penale. Nápoli: Morano, 1960.

CASTELLS, Manuel. A Galáxia da Internet: Reflexões sobre a internet, os negócios e a sociedade. Rio de Janeiro: Zahar, 2003.

CASTELLS, Manuel. A Sociedade em Rede, v. 1. São Paulo: Paz e Terra, 1999.

CASTELLS, Manuel. Redes de Indignação e Esperança: Movimentos Sociais na era da internet. Rio de Janeiro: Zahar, 2013.

FERRAJOLI. Luigi. Derecho y Razón: teoria del garantismo penal. Madrid: Trotta, 1999.

GIACOMOLLI, Nereu José. O Devido Processo Penal. Abordagem Conforme a Constituição Federal e o Pacto de São José da Costa Rica. São Paulo: Atlas/Gen, 2016.

GOMES FILHO, Antônio Magalhães. Presunção de Inocência e Prisão Cautelar. São Paulo: Saraiva, 1991.

HABERMAS, Jürgen. Mudança Estrutural da Esfera Pública: Investigação quanto a uma categoria da sociedade burguesa. Tradução de Flávio R. Kothe. Rio de Janeiro: Tempo Brasileiro, 1984.

ILLUMINATI, Giulio. La presunzione d' innocenza dell' imputato. Bologna: Zanichelli. 1984.

KARAM, Francisco José Castilhos. Alguns apontamentos e um futuro aberto: sociedade da informação e do conhecimento, convergência tecnológica, diversidade midiática e ciberjornalismo. Revista FAMECOS: Mídia, Cultura e Tecnologia. Porto Alegre, v. 17, n 3 p. 278 a 285, setembro/dezembro 2010. Disponível em: < http://revistaseletronicas.pucrs.br/ojs/ index.php/ revistafamecos/article/view/8195/5884> Acesso em: 01/11/2015;

LEITÃO, Helio. O Pijama do Pitta. Ordem dos Advogados do Brasil. Conselho Federal. Brasília, [2008]. Disponível em <http://www.oab.org.br/noticia/14552/ artigo-o-pijama-do-pitta>. Acesso em: 27/11/2016.

LOPES JR. Direito Processual Penal. São Pawulo: Saraiva, 2013.

MARQUES, Gil da Costa; CRESPO, Marcelo Xavier de Freitas. Um panorama sobre a Sociedade de Informação: o cloud computing e alguns aspectos jurídicos no ambiente digital. In: MENDES, Gilmar Ferreira; SARLET Ingo Wolfgang; COELHO, Alexandre Zavaglia P. (Coords.). Direito, Inovação e Tecnologia, v. 1. São Paulo: Saraiva, 2015.

MARTINS, Eduardo. O Estado de São Paulo: Manual de Redação e Estilo. 3 ed. São Paulo: O Estado de São Paulo, 1997, p. 31. Disponível em: <http://naui.ufsc.br/files/2010/09/Manualde-Reda\%C3\%A7\%C3\%A3o-e-Estilo_O-Estado-de-S\%C3\%A3o-Paulo.pdf.>. Acesso em: 27/11/2016.

MARTINS, Rui Cunha. O Ponto Cego do Direito: The Brazilian Lessons. Rio de Janeiro: Lumen Juris, 2010.

MORAES, Maurício Zanoide de. Presunção de Inocência no Processo Penal Brasileiro: análise de sua estrutura normativa para a elaboração legislativa e para a decisão judicial. Rio 
de Janeiro: Lumen Juris, 2010.

PRADO, Geraldo. O trânsito em julgado da decisão condenatória. Boletim IBCCRIM, ano 23, no 277, p. 10 a 12, dezembro/2015.

QC, Timothy Otty. The presumption of innocence and the right to a fair trial in international law. Boletim IBCCRIM, ano 23, n 277, p. 24 a 27, dezembro/2015.

SARLET, Ingo Wolfgang. Notas sobre as relações entre a Constituição Federal de 1988 e os Tratados Internacionais de Direitos Humanos na perspectiva do assim chamado Controle de Convencionalidade. In: MARINONI, Luiz Guilherme; MAZZUOLI, Valério de Oliveira. Controle de Convencionalidade: um panorama latino-americano. Brasília: Gazeta Jurídica, 2013.

SARLET, Ingo Wolfgang. A Eficácia dos Direitos Fundamentais. Porto Alegre: Livraria do Advogado, 2015.

SARLET, Ingo Wolfgang. Direitos Fundamentais e Direito Privado: algumas considerações em torno da vínculação dos particulares aos direitos fundamentais. In: SARLET, Ingo Wolfgang. A Constituição Concretizada. Porto Alegre: Livraria do Advogado, 2000

SARLET, Ingo Wolfgang; MARINONI, Luiz Guilherme; MITIDIERO, Daniel. Curso de Direito Constitucional. São Paulo: RT, 2013.

SCHOPENHAUER, Arthur. A arte de ter razão. São Paulo: Martins Fontes, 2009.

SCHREIBER, Simone. Entrevista ao CONJUR. Disponível em: <http://www.conjur.com.br/2008jun-29/liberdade_expressao_nao_direito_absoluto>. Acesso em: 20/10/2015.

SCHREIBER, Simone. O princípio da presunção de Inocência. Instituto dos Advogados do Brasil, Revista Digital, Rio de Janeiro, no 10, p. 85 a 101, Abr-Jun.2011. Disponivel em: < http://www.iabnacional.org.br/IMG/pdf/doc-5287.pdf>. Acesso em: 08/09/2015.

VAZAMENTO de dados: Ajufesp critica vazamento de informações na Operação Satiagraha. Consultor Jurídico, 8 de julho de 2008. Disponível em: <http://www.conjur.com.br/2008-jul08/ajufesp_critica_atuacao_pf_operacao_satiagraha>. Acesso em: 10/10/2016.

Recebido em: fevereiro/2017

Aprovado em: abril/2017 